\title{
CORRECTION
}

\section{Correction to: Relation of circulating estrogens with hair relaxer and skin lightener use among postmenopausal women in}

\section{Ghana}

Ashley M. Geczik, Roni T. Falk, Xia Xu, Beatrice Wiafe-Addai, Joel Yarney, Baffour Awuah, Richard Biritwum, Verna Vanderpuye, Florence Dedey, Ernest Adjei, Francis Aitpillah, Ernest Osei-Bonsu, Joseph Oppong, Nicholas Titiloye, Lawrence Edusei, Kofi Nyarko, Joe-Nat Clegg-Lamptey, Seth Wiafe, Daniel Ansong, Thomas U. Ahearn, Jonine Figueroa, Montserrat Garcia-Closas, Louise A. Brinton and Britton Trabert

(c) The Author(s), under exclusive licence to Springer Nature America, Inc. 2022

Journal of Exposure Science \& Environmental Epidemiology (2023) 33:311; https://doi.org/10.1038/s41370-022-00415-y

Correction to: J Expo Sci Environ Epidemiol https://doi.org/10.1038/ s41370-021-00407-4, published online 06 January 2022

In the original article the affiliation details for the authors Thomas U. Ahearn, Montserrat Garcia-Closas, Louise A. Brinton, and Britton Trabert were incorrectly given as

${ }^{2}$ Protein Characterization Laboratory, Leidos-Frederick, Inc, Frederick National Laboratory for Cancer Research, Frederick, MD, USA. but should have been

${ }^{1}$ Division of Cancer Epidemiology and Genetics, National Cancer Institute, National Institutes of Health, Bethesda, MD, USA.

The original article has been corrected. 